\title{
Cardiac Shock Wave Therapy Attenuates H9c2 Myoblast Apoptosis by Activating the AKT Signal Pathway
}

\author{
Weiwei Yua,b Tao Shen ${ }^{c}$ Baoyi Liu ${ }^{b}$ Shu Wang ${ }^{c}$ Jian Lic Dapeng Daic Jianping Caic \\ Qing $\mathrm{He}^{\mathrm{a}, \mathrm{b}}$
}

aGraduate School of Peking Union Medical College and Chinese Academy of Medical Sciences, Beijing, 'Department of Cardiology, Beijing Hospital, Beijing, 'Key Laboratory of Geriatrics, Beijing Hospital and Beijing Institute of Geriatrics, Ministry of Health, Beijing, China; 'These authors contributed equally to this work

\section{Key Words}

Cardiac Shock Wave Therapy $\cdot$ Ischemia/Hypoxia $\cdot$ Apoptosis $•$ AKT

\begin{abstract}
Background: Previous studies have demonstrated that Cardiac Shock Wave Therapy (CSWT) improves myocardial perfusion and cardiac function in a porcine model of chronic myocardial ischemia and also ameliorates myocardial ischemia in patients with severe coronary artery disease (CAD). Apoptosis plays a key role in ischemic myocardial pathogenesis. However, it remains unclear whether CSWT is beneficial for ischemia/hypoxia $(\mathrm{I} / \mathrm{H})$-induced myocardial cell apoptosis and by which mechanism CSWT could improve heart function. We put forward the hypothesis that CSWT might protect heart function during ischemia/hypoxia by decreasing apoptosis. Methods: We generated ischemia/hypoxia (I/H)-induced apoptosis in the H9c2 myoblast cell line to examine the CSWT function and possible mechanisms. H9c2 cells were treated under hypoxic serum-starved conditions for $24 \mathrm{~h}$ and then treated with or without CSWT (500 shots, $0.06,0.09,0.12 \mathrm{~mJ} / \mathrm{mm}^{2}$ ). The apoptotic cell rate was determined by flow cytometry assay, cell viability was examined by the MTT assay, nuclear fragmentation was detected by Hoechst 33342 staining, and the mitochondrial-mediated intrinsic pathway of apoptosis was assessed by the expression of $\mathrm{Bax}$ and $\mathrm{BCl}-2$ protein and Caspase 3 activation. Results: First, apoptosis could be induced by ischemia/hypoxia in H9c2 cells. Second, CSWT attenuates the cell death and decreases the H9c2 cell apoptosis rate induced by ischemia and hypoxia. Third, CSWT suppresses the expression of apoptosis molecules that regulate the intrinsic pathway of apoptosis in H9c2 cells. Fourth, CSWT increases the phosphorylation of AKT, which indicates the activation of the PI3K-AKT pathway. Conclusions: These results indicate that CSWT exerts a protective effect against $\mathrm{I} / \mathrm{H}$-induced cell death, potentially by preventing the activation of components of the mitochondrial-dependent intrinsic apoptotic pathway. We also demonstrate that the PI3K-Akt pathway may be involved in the CSWT effects on apoptosis.
\end{abstract}

Copyright $\odot 2014$ S. Karger AG, Basel

Prof. Qing $\mathrm{He}$,

and Jianping Cai
Department of Cardiology, Beijing Hospital, No. 1, Dahua Road, Dong Dan, Beijing 100730 (China); and Key Laboratory of Geriatrics, Beijing Hospital and Beijing Institute of Geriatrics, Ministry of Health, Beijing, (China)

E-Mail heqingli2001@yahoo.com and E-Mail caijp61@vip.sina.com 


\section{Cellular Physiology and Biochemistry}

Cell Physiol Biochem 2014;33:1293-1303

DOI: $10.1159 / 000358697$

Published onIIne: April 28, 2014

C) 2014 S. Karger AG, Basel

www.karger.com/cpb

\section{Introduction}

Coronary artery disease (CAD) is a leading cause of morbidity and mortality worldwide [1]. The current therapeutic options are dependent on medical treatment, percutaneous coronary intervention (PCI), and coronary artery bypass grafting (CABG). With these three therapies, we have achieved significant improvement in morbidity and mortality [2]. However, the prognosis of patients with severe ischemic heart disease but without efficacious revascularization remains poor [3]. Therefore, it is crucial to develop alternative therapeutic strategies for these patients.

Cardiac Shock Wave Therapy (CSWT) is currently the most advanced technology developed in recent years. CSWT induces angiogenesis through the up-regulation of VEGF in ischemic myocardium and ameliorates myocardial ischemia and dysfunction in a porcine model of chronic myocardial ischemia, increasing myocardial perfusion and improving the patient's symptoms of angina and heart function [4-6].

Apoptosis plays a key role in the pathogenesis of CAD due to the loss of myocardial cells. It has been reported that patients with end-stage congestive heart failure and myocardial infarction have higher rates of myocardial cell apoptosis than normal subjects [7-10]. Apoptosis is a highly regulated program of cell death and can be mediated by two pathways, the extrinsic and intrinsic pathway, leading to Caspase activation. The cell death program is activated in myocardial cells by various apoptotic stimuli, including hypoxia, cytokines, increased oxidative stress, and DNA damage. Many studies have demonstrated that the inhibition of apoptosis can prevent the development of heart failure and improve heart function [11-14].

Recent studies have demonstrated that CSWT improves myocardial perfusion and cardiac function in a porcine model of chronic myocardial ischemia and also ameliorates myocardial ischemia in patients with severe CAD. Nonetheless, it is not clear whether CSWT has any beneficial effect on ischemia/hypoxia $(\mathrm{I} / \mathrm{H})$-induced myocardial cell apoptosis and the mechanisms by which CSWT could improve heart function. Based on the promising results from animal and clinical studies, we put forward the hypothesis that CSWT can attenuate myocardial cell apoptosis. This study utilized an H9c2 cell ischemia/hypoxia model to test the effects of CSWT on apoptosis and to explore the possible mechanism of CSWT in improving myocardial function.

\section{Materials and Methods}

\section{H9c2 cell culture}

H9c2 myoblast cells were obtained from the American Type Culture Collection (ATCC, Rockville, MD); all of the cell culture reagents were obtained from Invitrogen Corporation (Carlsbad, CA). The H9c2 cells were cultured in Dulbecco's modified Eagle's medium supplemented with 10\% fetal bovine serum, $25 \mathrm{mM}$ glucose, $2 \mathrm{mM}$ glutamine, $100 \mu \mathrm{g} / \mathrm{ml}$ penicillin and $100 \mu \mathrm{g} / \mathrm{ml}$ streptomycin. The cells were maintained in a humidified incubator with $5 \% \mathrm{CO}_{2}$ at $37^{\circ} \mathrm{C}$, passaged regularly, and subcultured to approximately $70 \%$ to $80 \%$ confluence pre-experimentally.

\section{Simulated ischemia/hypoxia model}

To induce apoptosis, the culture medium was replaced with serum-free Dulbecco's modified Eagle's medium, and the cells were transferred into a hypoxia chamber controlled by a ProOxC system balanced with $5 \% \mathrm{CO}_{2} / 95 \% \mathrm{~N}_{2}$ (Biospherix, Redfield, $\mathrm{NY}$ ) for the indicated periods at $37^{\circ} \mathrm{C}$. To determine the appropriate time to induce apoptosis, the H9c2 cells were treated under the ischemia/hypoxia conditions for 12, 24, 36, or $48 \mathrm{~h}$.

Shock wave therapy

After incubation under I/H conditions for $24 \mathrm{~h}$, the cells used for CSWT were transferred to special tubes $\left(2 \mathrm{ml}\right.$ tube, $5 \times 10^{6}$ cells $\left./ \mathrm{ml}\right)$. Shock waves were produced by the CSWT system (Modulith SLC, Storz 


\section{Cellular Physiology and Biochemistry}

Cell Physiol Biochem 2014;33:1293-1303

\begin{tabular}{l|l}
\hline DOI: $10.1159 / 000358697$ & (C) 2014 S. Karger AG, Basel
\end{tabular}

www.karger.com/cpb

Yu et al.: CSWT Attenuates Cell Apoptosis

Medical, Switzerland), and the shock wave pulse was easily focused on the tube. We treated the H9c2 cells with 500 shots of shock wave at three different energy levels ( 0 [control], $0.06,0.09$, and $\left.0.12 \mathrm{~mJ} / \mathrm{mm}^{2}\right)$ and then cultured the cells for $24 \mathrm{~h}$ under normal conditions [4]. Moreover, two groups incubated under normal conditions and treated with CSWT $\left(0.12 \mathrm{~mJ} / \mathrm{mm}^{2}\right)$ or without CSWT were evaluated as another control.

Flow cytometry assay

The percentage of cells that underwent apoptosis or necrosis was determined using the Annexin V-FITC and propidium iodide (PI) Analysis kit according to the manufacturer's instructions. The cells were harvested, washed twice with cold $1 \mathrm{X}$ phosphate-buffered saline (PBS), and resuspended in $1 \mathrm{ml}$ cold 1X binding buffer. A 100- $\mu$ l aliquot of the cell suspension was stained with $5 \mu$ l of Annexin V-FITC for 10 minutes in the dark and at room temperature; $5 \mu \mathrm{l}$ of PI was then added for $5 \mathrm{~min}$ at room temperature, protected from light, and PBS was added to $500 \mu \mathrm{l}$. Flow cytometry was carried out using a FACScan instrument, and the data were processed using WinMDI/PC software.

\section{Cell viability assay}

Cell viability was examined by the MTT assay according to the instructions of the manufacturer. H9c2 cells were plated in 96-well plates. The cells were pre-treated with I/H for $24 \mathrm{~h}$ and then treated with CSWT. The cells were incubated with $0.5 \mathrm{mg} / \mathrm{ml} \mathrm{3-[4,5-dimethylthiazol-2-yl]-2,5-diphenylterazolium} \mathrm{bromide} \mathrm{for}$ $4 \mathrm{~h}$, and the absorbance at $490 \mathrm{~nm}$ was measured, as described previously [15]. The mean optical density (OD) of six wells in the indicated groups was used to calculate the percentage of cell viability according to the following formula: percentage of cell viability $=$ OD treatment group/OD control group $\times 100 \%$. The experiments were preformed in quadruplicate.

\section{Hoechst 33342 staining}

Nuclear fragmentation was detected by incubating fixed cells in $10 \mathrm{mmol} / \mathrm{L}$ Hoechst 33342, as previously described [15]. A total of 500-700 cells in 10 randomly chosen fields from each dish were counted to determine the percentage of apoptotic nuclei. The morphological features of apoptosis (chromatin condensation and nuclear fragmentation) were monitored by fluorescence microscopy. Each data point shows the results from 5000-7000 cells of 4-8 independent experiments.

Western blot analysis

Cell lysates (15-30 $\mu$ g of protein) were separated by 12\% SDS-PAGE, transferred to PVDF membranes (Millipore), blocked with $5 \%$ nonfat dry milk, and probed with antibodies at $4{ }^{\circ} \mathrm{C}$ overnight. The blots were incubated with HRP-conjugated anti-IgG, followed by detection with ECL (Millipore). Rat monoclonal antibodies against Bax, Bcl-2, Caspase-3, AKT, p-AKT, ERK, p-ERK, p38 MAPK, and p-p38 MAPK were purchased from Cell Signal Technology. The levels of staining for target proteins were normalized to those for $\beta$-actin as an internal control. ImageJ software was used to perform the densitometric analysis.

\section{Statistical analysis}

All of the statistical calculations were performed using the GraphPad Prism 5 software program. The data were expressed as the mean \pm SEM. Student's t-test was used to compare two conditions, and a oneway ANOVA with Bonferroni correction was used for multiple comparisons. P values of less than 0.05 were considered significant.

\section{Results}

H9c2 cell apoptosis is induced by ischemia/hypoxia

To choose the appropriate time to induce apoptosis, H9c2 cells were cultured under I/H conditions for $12 \mathrm{~h}, 24 \mathrm{~h}, 36 \mathrm{~h}$, or $48 \mathrm{~h}$ and showed a significant time-dependent reduction in cell viability compared to the control, as assayed by the MTT assay (Fig. 1A). The H9c2 cell viability was decreased by $26 \%$ after incubation under $\mathrm{I} / \mathrm{H}$ conditions for $24 \mathrm{~h}$, which is a medium degree of cell injury. Therefore, cells incubated under I/H conditions for $24 \mathrm{~h}$ were used in the subsequent experiments. After incubation under I/H conditions for $24 \mathrm{~h}, \mathrm{H} 9 \mathrm{c} 2$ 

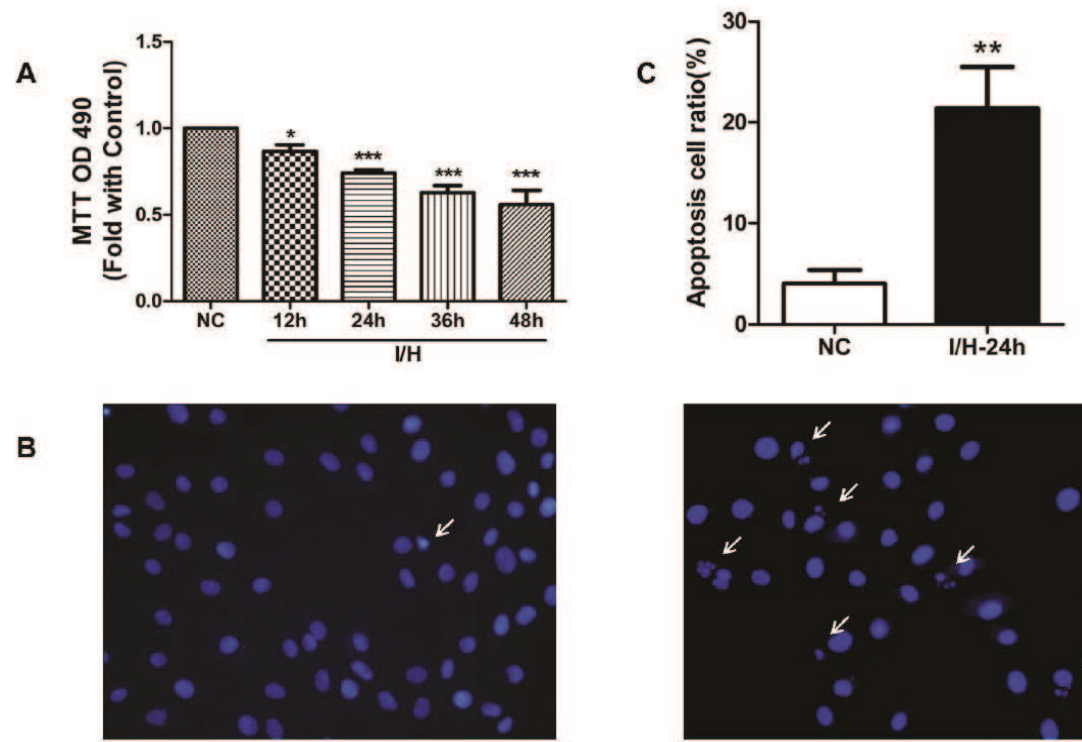

NC

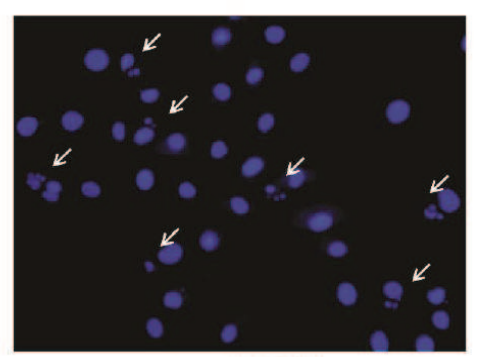

I/H-24h

Fig. 1. Ischemia/hypoxia induced H9c2 cell apoptosis. The H9c2 cells were incubated in standard DMEM (NC) or in ischemia/Hypoxia conditions (I/H). (A): The effects of simulated ischemia/hypoxia on the cell viability. I/H markedly increased H9c2 cells death assayed by MTT. (B): Ischemia/Hypoxia markedly increased H9c2 cell death assayed by Hoechst 33342 staining (white arrow indicates the apoptotic body or apoptotic nucleus) and the average data (C). $\mathrm{n}=4$, Mean \pm SEM. ${ }^{*} \mathrm{P}<0.05,{ }^{* *} \mathrm{P}<0.01,{ }^{* * *} \mathrm{P}<0.001$ vs NC.

Fig. 2. The H9c2 cells were treated by Ischemia/Hypoxia for $12 \mathrm{~h}, 24 \mathrm{~h}, 36 \mathrm{~h}$, and $48 \mathrm{~h}$. (A): Western blotting was used to analysis of Caspase 3 abundance in $\mathrm{H} 9 \mathrm{c} 2$ cells. After incubate in $\mathrm{I} / \mathrm{H}$ conditions for $24 \mathrm{~h}$, the cleaved Caspase 3 protein was begun to be detected. (B): The average data of Cleaved-Caspase3 in $\mathrm{H} 9 \mathrm{c} 2$ cells. $\mathrm{n}=5$, Mean \pm SEM. ** $\mathrm{P}<0.01$ vs NC.

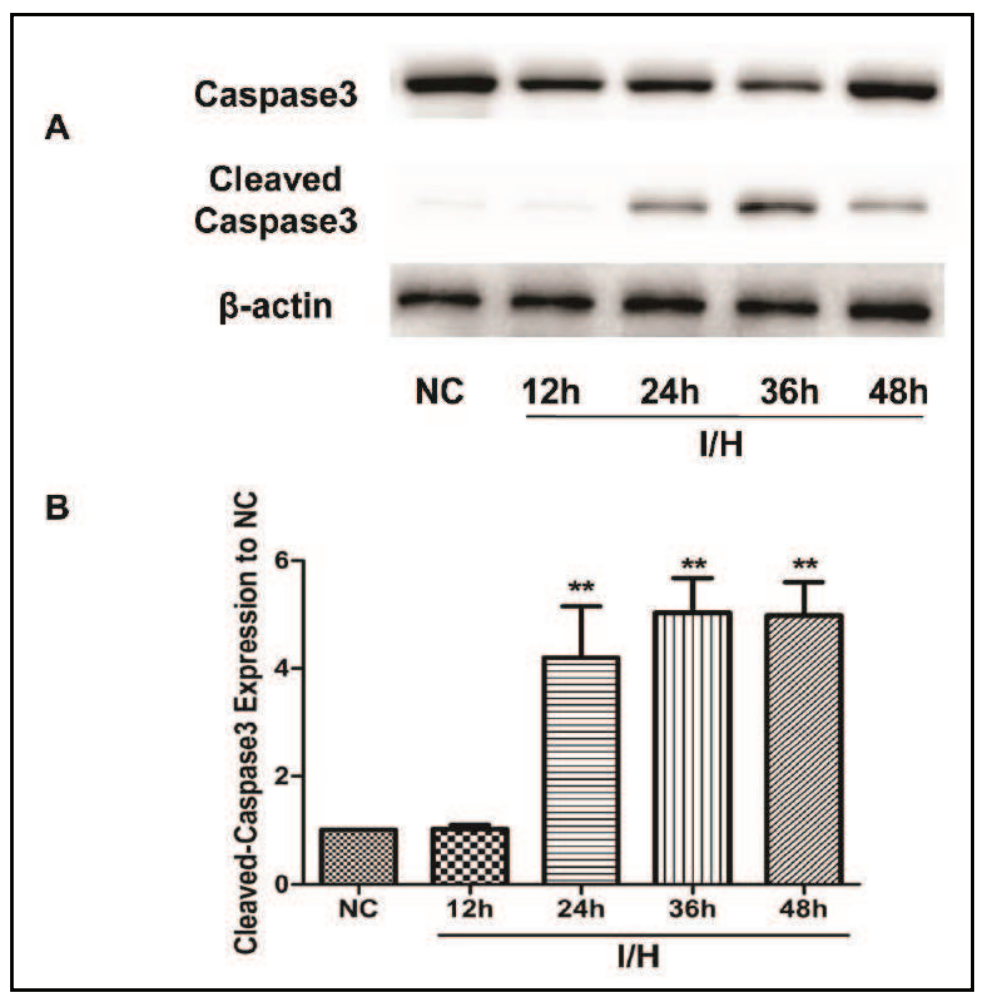

cell apoptosis was markedly increased, as assayed by Hoechst staining (Fig. 1B-1C), and less full-length caspase 3 and more cleaved caspase 3 was found compared to the NC group (Fig. 2).This result suggested that it is appropriate to incubate under $\mathrm{I} / \mathrm{H}$ conditions for $24 \mathrm{~h}$ to induce apoptosis. 


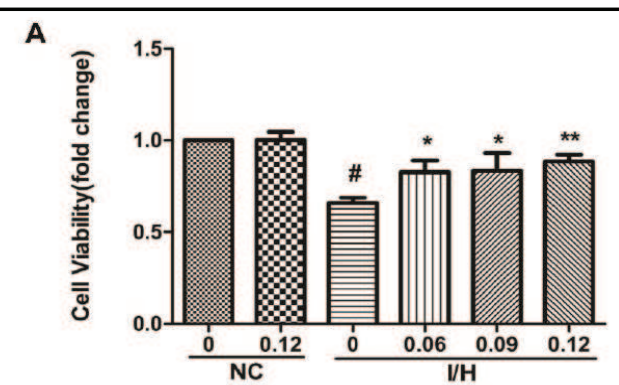

B

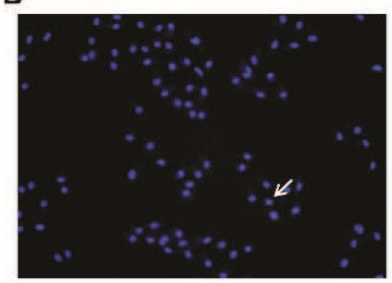

NC

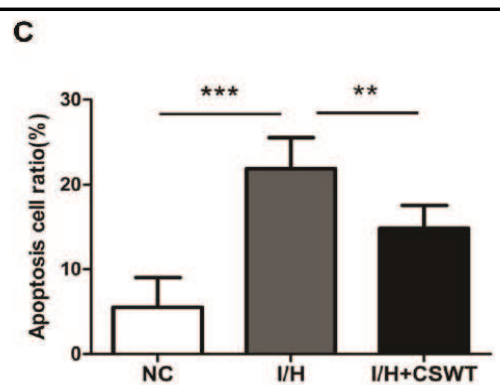

I/H

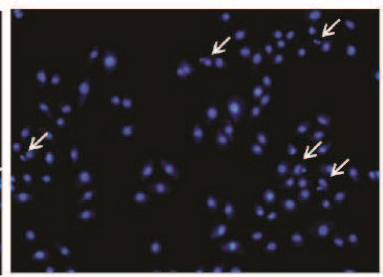

$\mathrm{I} / \mathrm{H}+\mathrm{CSWT}$

Fig. 3. CSWT attenuates the cellular death induced by ischemia in the H9c2 cells. The H9c2 cells were incubated in standard DMEM (NC) or in I/H culture conditions with (I/H+CSWT) or without CSWT (I/H). (A): The H9c2 cell viability as shown by MTT assay. $\mathrm{n}=4$. Mean $\pm \mathrm{SEM}$. ${ }^{*} \mathrm{P}<0.05$ vs $\mathrm{NC}-0,{ }^{*} \mathrm{P}<0.05,{ }^{* *} \mathrm{P}<0.01$ vs I/H-0. (B, C): CSWT markedly reduced H9c2 cell death, assayed by Hoechst 33342 staining. $n=4$. Mean \pm SEM. ${ }^{* *} \mathrm{P}<0.01,{ }^{* * *} \mathrm{P}<0.001$ vs $\mathrm{I} / \mathrm{H}$.

A

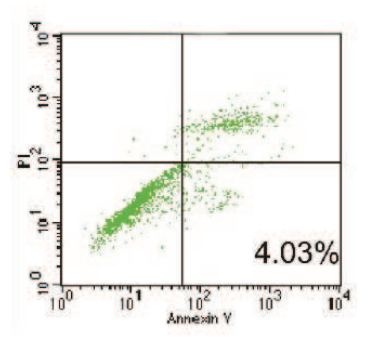

NC

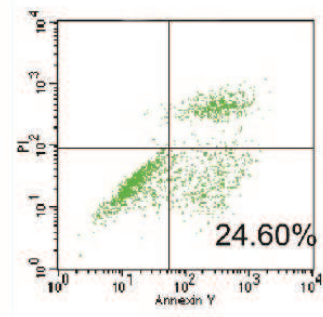

I/H

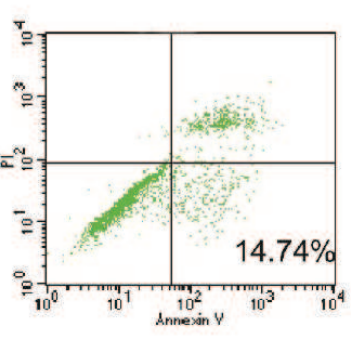

I/H+CSWT

B

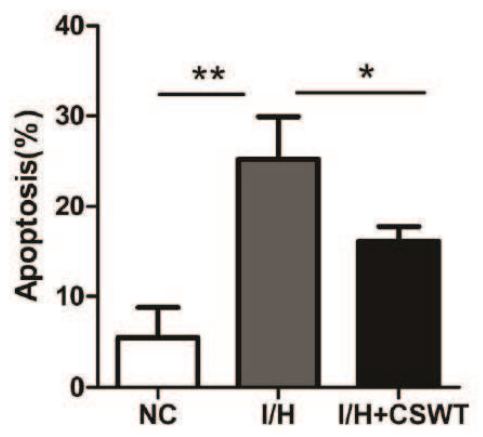

Fig. 4. CSWT decreased I/H-induced H9c2 cell apoptotic rate by Flow Cytometry Assay. The H9c2 cells were incubated in standard DMEM (NC) or in I/H culture conditions with $(\mathrm{I} / \mathrm{H}+\mathrm{CSWT}$ ) or without CSWT (I/H). The cells were labeled with a combination of FITC-Annexin $\mathrm{V}$ and propidium iodide (PI). The percentage of early apoptotic cells (lower right quadrant) is indicated. $\mathrm{n}=3$. Mean $\pm \mathrm{SEM}$. ${ }^{*} \mathrm{P}<0.05,{ }^{*} \mathrm{P}<0.01 \mathrm{vs} \mathrm{I/H}$.

CSWT attenuates the cell death induced by ischemia and hypoxia in H9c2 cells

CSWT significantly reduced I/H-induced cell death and increased cell viability. Compared to treatment with $\mathrm{I} / \mathrm{H}$ alone, cell viability was strongly enhanced after CSWT treatment, with 


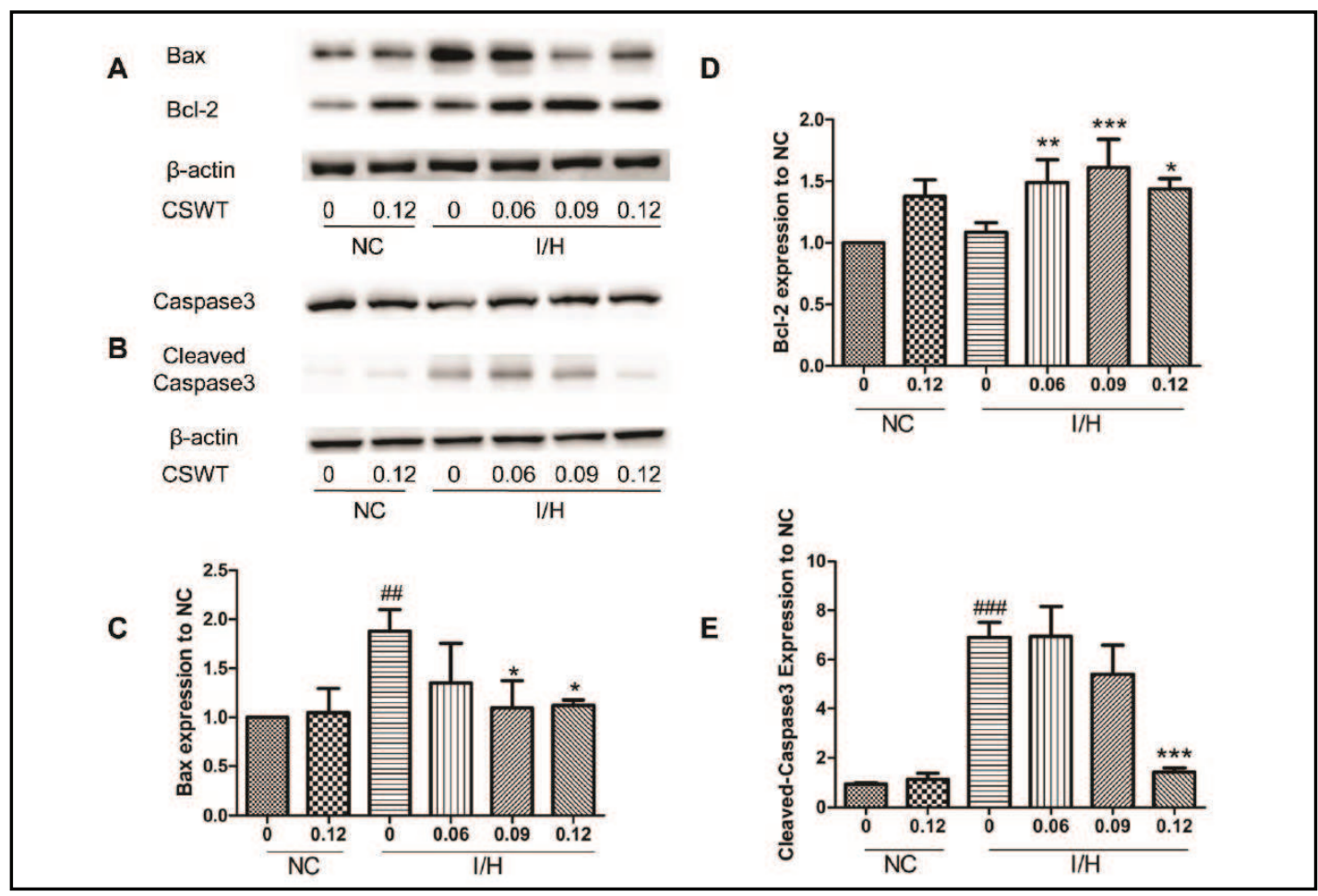

Fig. 5. CSWT suppresses the expression of apoptosis molecules induced by I/H. The H9c2 cells were incubated in standard DMEM (NC) or in I/H culture conditions with or without CSWT. (A, B): Western blotting analysis of Bax, Bcl-2, Caspase 3 abundance in H9c2 cells. (C, D, E): The average data of Bax, Bcl-2, Caspase3 in H9c2 cells. $\mathrm{n}=3$, Mean \pm SEM. ${ }^{\# \#} \mathrm{P}<0.01,{ }^{\# \# \#} \mathrm{P}<0.001$ vs $\mathrm{NC}-0,{ }^{*} \mathrm{P}<0.05,{ }^{* *} \mathrm{P}<0.01,{ }^{* * *} \mathrm{P}<0.001$ vs $\mathrm{I} / \mathrm{H}-0$.

a maximum effect at $0.12 \mathrm{~mJ} / \mathrm{mm}^{2}$ (Fig. 3A). Moreover, the apoptotic effect of I/H was further manifested by $\mathrm{I} / \mathrm{H}$-induced increases in chromatin condensation and fragmentation, which was demonstrated by Hoechst 33342 nuclear staining. As shown in Fig. 3B-3C, chromatin condensation was decreased and the cell density was increased compared to the I/H group.

CSWT decreases the I/H-induced H9c2 cell apoptosis rate by flow cytometry

H9c2 cells were incubated in standard DMEM (NC) or under I/H culture conditions with $(\mathrm{I} / \mathrm{H}+\mathrm{CSWT})$ or without CSWT $(\mathrm{I} / \mathrm{H})$. In a previous study (Fig. $3 \mathrm{~A})$, there was a maximum effect noted at $0.12 \mathrm{~mJ} / \mathrm{mm}^{2}$; thus, we choose $0.12 \mathrm{~mJ} / \mathrm{mm}^{2}$ as a treatment condition in subsequent experiments. FITC-Annexin V/propidium iodide staining showed that $\mathrm{I} / \mathrm{H}$ treatment for $24 \mathrm{~h}$ induced apparent early apoptosis in H9c2 cells. As shown in Fig. 4A, the control and I/H groups showed early apoptosis at rates of 4.03 and $24.60 \%$, respectively. After treatment with CSWT $\left(0.12 \mathrm{~mJ} / \mathrm{mm}^{2}\right)$, the early apoptosis rate was reduced to $14.74 \%$, which was significantly different (Fig. 4B). The results indicate that CSWT could reduce the early apoptosis induced by $\mathrm{I} / \mathrm{H}$ in $\mathrm{H} 9 \mathrm{c} 2$ cells.

CSWT suppresses the expression of apoptosis molecules induced by $I / H$

To examine the mechanism of CSWT's protective effect on I/H-induced apoptosis in $\mathrm{H} 9 \mathrm{c} 2$ cells, we analyzed the protein expression of Bax, Bcl-2, and Caspase3, which play important roles in regulating the intrinsic pathway of apoptosis in myocardial cells. Bcl-2 is an anti-apoptosis protein, and the expression of bcl-2 was significantly increased in the CSWT treatment group $\left(0.06,0.09\right.$, and $\left.0.12 \mathrm{~mJ} / \mathrm{mm}^{2}\right)$ compared to the $\mathrm{I} / \mathrm{H}$ group, whereas its expression was increased in the NC group treated with CSWT $\left(0.12 \mathrm{~mJ} / \mathrm{mm}^{2}\right)$. CSWT $(0.09$, $0.12 \mathrm{~mJ} / \mathrm{mm}^{2}$ ) also decreased the expression of pro-apoptosis protein Bax compared to the 

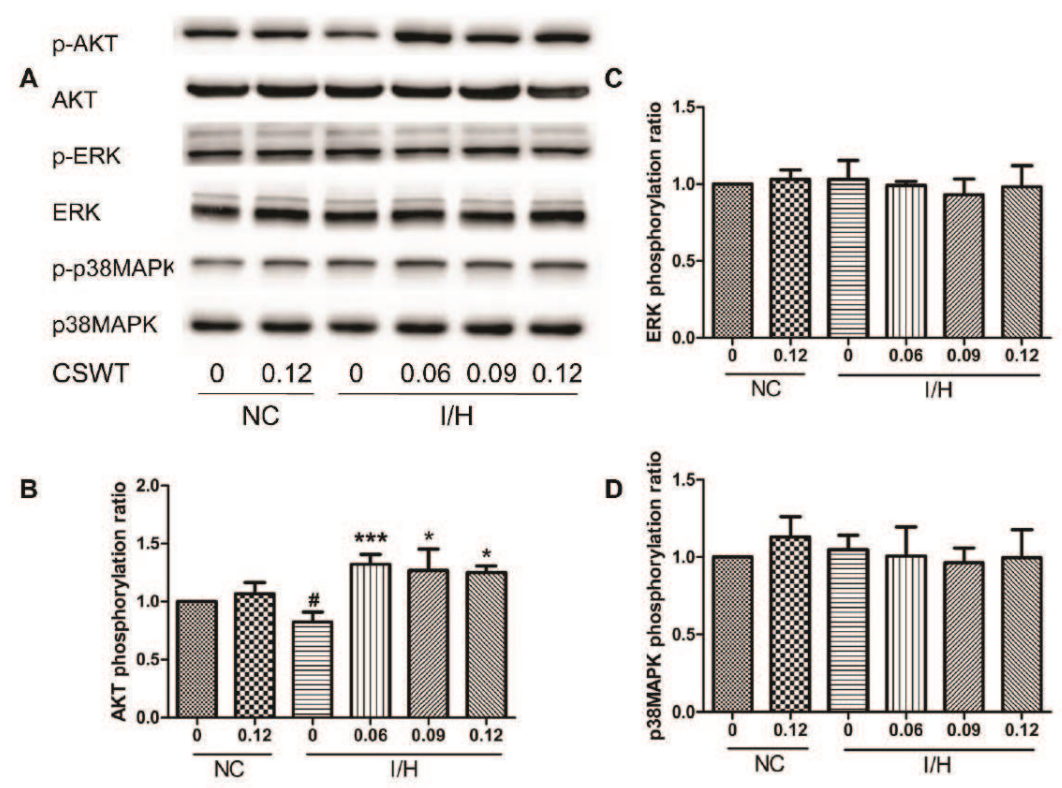

Fig. 6. CSWT's anti-apoptotic effects are mediated through AKT-dependent signaling pathways. The H9c2 cells were incubated in standard DMEM (NC) or in I/H culture conditions with or without CSWT. (A): Western blotting analysis of p-AKT, AKT, p-ERK, ERK, p-p38MAPK and p38MAPK abundance in H9c2 cells. (B, C, D): The average data of AKT phosphorylation, ERK phosphorylation and p38MAPK phosphorylation in $\mathrm{H} 9 \mathrm{c} 2$ cells.

I/H group (Fig. 5A). Moreover, we detected cleaved Caspase3, as shown in Fig. 5B. CSWT $\left(0.12 \mathrm{~mJ} / \mathrm{mm}^{2}\right)$ could significantly reduce the activation ofCaspase 3 . The results indicate that CSWT of the appropriate energy suppresses the expression of apoptosis molecules induced by I/H.

The AKT pathway may be involved in the CSWT effects on apoptosis

Because we found that CSWT inhibited the Bax and cleaved caspase 3 expression induced by $\mathrm{I} / \mathrm{H}$, we speculated that CSWT might affect PI3K-AKT activation. Compared with the I/H group, CSWT $\left(0.06,0.09,0.12 \mathrm{~mJ} / \mathrm{mm}^{2}\right)$ increased the phosphorylation of AKT (Fig. $6 \mathrm{~A}$ ), though there was no significant difference between the $\mathrm{NC}$ and $\mathrm{NC}+\mathrm{CSWT}$ groups with regard to the AKT ratio. We also determined whether other MAPK signal pathways, such as the p38 MAPK and ERK signaling pathways, could mediate the protective effect of CSWT on $\mathrm{I} / \mathrm{H}$-induced myocardial cell apoptosis. We found that there were no significant differences in the phosphorylation of p38 MAPK and ERK between the CSWT and I/H groups (Fig. 6A). The results indicate that CSWT's anti-apoptotic effects are mediated through AKT-dependent signaling pathways.

\section{Discussion}

The novel findings of this study are that CSWT can attenuate H9c2 myoblast apoptosis and that the activation of the AKT signaling pathway may be involved in the CSWT effects on apoptosis. To our knowledge, there are few reports that CSWT can attenuated the H9c2 cell apoptosis induced by $\mathrm{I} / \mathrm{H}_{0}$.

Primary cardiac myocytes are widely used in cardiac studies; however, the major disadvantage of these cells is the large number of animals that are required. H9c2 rat cardiomyocytes demonstrate many similarities to primary cardiomyocytes [16], and some previous studies have used hypoxia-induced $\mathrm{H} 9 \mathrm{c} 2$ cell line models to replace myocardiocytes 


\section{Cellular Physiology and Biochemistry}

Cell Physiol Biochem 2014;33:1293-1303

\begin{tabular}{l|l}
\hline DOI: $10.1159 / 000358697$ & (C) 2014 S. Karger AG, Basel
\end{tabular}

www.karger.com/cpb

Yu et al.: CSWT Attenuates Cell Apoptosis

[17-19]. TheH9c2 rat cardiomyocyte cell line is a reliable alternative for some studies and was used in all of our experiments. In the model of simulated ischemia-induced apoptosis herein, simulated ischemia significantly caused caspase 3 activation, signs of nuclear apoptosis, and increasing amounts of dead cardiac myocytes. Although these results prove that this is a reliable model, further study in vivo should be carried out in the future.

CSWT is a new technology, and some studies have been made in European nations such as Switzerland, Germany, Italy, Russia, and Japan at present, achieved some good effect, and made a tendency to gradually expand the application [20-24]. Although many clinical studies have preliminary confirmed that CSWT can treat myocardial ischemia, improving the patient's symptoms, the precise mechanism by which this occurs remains unclear. Apoptosis plays an important role in ischemic diseases, but there are few reports on whether CSWT treatment can attenuate apoptosis in myocardial cells. Due to this lack of studies, we attempted to establish a model of ischemia and hypoxic cells and use the myocardial cell injury model to explore whether CSWT could attenuate apoptosis.

Tanaka et al. [25] found that hypoxia causes apoptosis in cultured myocardial cells in vitro. Kajstura et al. [26] and Leri et al. [27] also found that hypoxia causes myocardial cell apoptosis in vivo, and several other studies have reported that the apoptosis induced by ischemia/hypoxia is mainly dependent on the activation of mitochondrial pathways in cells [28].Apoptosis is regulated by Bcl-2 family proteins, the members of which are pro-apoptotic or anti-apoptotic. Bax is an important factor leading to apoptosis under hypoxic stress. In response to apoptotic stimuli, Bax undergoes conformational activation and then facilitates the release of cytochrome c from mitochondria [29]. In contrast, Bcl-2 has the ability to suppress this Bax-induced release of cytochrome c from mitochondria [30, 31]. Hypoxia decreases Bcl-2 expression in myocardial cells [32,33], and the expression ratio of Bcl-2 to Bax was reported to determine cell survival or death following an apoptotic stimulus. Bax and Bcl-2 play important physiological roles in the protection or acceleration of apoptosis in human myocardial cells after ischemia and/or reperfusion. We adopted the method of ischemia and hypoxia experiments to induce apoptosis. In our experiment, the viability of myocardial cells decreased notably after ischemia and hypoxia for $24 \mathrm{~h}$. The apoptotic cell rate began to increase compared with the control cells, as indicated by increased Bax and Caspase 3 expression and reduced $\mathrm{Bcl}-2$ expression.

It has been reported that the apoptosis induced by ischemia and hypoxia plays an important role in the development in CAD: the loss of myocardial cells causes abnormal loading conditions, which may induce LV dilatation and a gradual decline in LV contractility during the chronic phase [1]. The development of LV remodeling leads to heart failure. Recent studies have demonstrated that CSWT improves myocardial perfusion and cardiac function in a porcine model of chronic myocardial ischemia and also ameliorates myocardial ischemia in patients with severe CAD. In chronic ischemia animal experiments, it was observed that CSWT could induce a complete recovery of the left ventricular ejection fraction, wall thickening fraction, and regional myocardial blood flow. In AMI pig models [34], CSWT normalized the LV ejection fraction in the SW group but not in the control group. In the present study, we investigated whether CSWT had any effect on cardiomyocyte apoptosis in vitro. We observed that CSWT attenuated the cell death induced by I/H in H9c2 cells, the expression of bcl-2 was significantly increased, and the expression of Bax and cleaved Caspase 3 were decreased. Our studies clearly demonstrate for the first time that CSWT attenuates the intrinsic pathway of apoptosis in cardiomyocytes.

To further explore the regulation mechanism by which CSWT attenuates intracellular myocardial cell apoptosis, three MAPK intracellular signal pathways were detected at the same time: the AKT, ERK, and p38MAPK pathways. We found that under the intervention of CSWT, AKT phosphorylation increased significantly, whereas ERK and p38MAPK phosphorylation had no significant change, which suggests that the AKT pathway may be involved in the effects of CSWT on apoptosis. The AKT signaling pathway is closely related to growth, proliferation, and apoptosis inhibition, playing an important role in maintaining cell survival [35]. AKT is the most important factor for mediating these PI3K-dependent 


\section{Cellular Physiology and Biochemistry}

Cell Physiol Biochem 2014;33:1293-1303

DOI: $10.1159 / 000358697$

Published onlıne: April Z8, 2014

C) 2014 S. Karger AG, Basel

www.karger.com/cpb

cell-survival responses. Previous studies have established the principle role of AKT in the regulation of cell survival in several cell types. The pro-apoptotic Bcl-2-family member BAD inhibits Bcl-2 and other anti-apoptotic Bcl-2 family members by direct binding when it is not phosphorylated [36], and AKT can phosphorylate BAD to regulate cell survival in IL-3dependent myeloid cells [37] and in fibroblasts and primary neurons [38]. In our study, we found that the AKT pathway may be involved in the effects of CSWT on apoptosis, but more detailed mechanistic analyses are required.

To date, several reports about shock wave application in experimental myocardial ischemia have been published, showing effectiveness in CAD. However, there also has some conflicting viewpoint for CSWT, indicating that CSWT can cause irreversible myocardial damage and may cause an injury-and-repair process, which is expected to result in fibrosis and functional loss of the myocardium [39, 40]. Given the lack of safety studies, an Italy study evaluates the safety of CSWT on the adult heart and its effects on cardiac tissue function and morphology. Four-month-old Fisher 344 rats were treated by CSWT. Cardiac function was measured by echocardiogram at baseline and at 1 and 3 months after treatment. The left ventricular ejection fraction and fractional shortening remained stable at all time points. Immunohistochemistry was used to evaluate the signs of inflammation, apoptosis and fibrosis in the control and treated hearts. There were neither differences in the extracellular matrix collagen content nor the presence of fibrosis. Moreover, CSWT did not increase the apoptosis of cardiac cells in treated hearts in vivo, and there were no signs of inflammation at 3 months after CSWT treatment [41]. Meanwhile, myocardial ischemia mini-pigs were used in Fu's study, they found that there were lower mean fibrosis area and apoptotic nuclei in CSWT treated group compared to ischemia group by immunohistochemical staining at day 180 [42]. According to the results of the animal experiments and preliminary clinical trial observation, we think that CSWT is a safe and effective way to treat ischemic heart disease.

Several limitations should be mentioned for this study. First, although we were able to demonstrate that CSWT could attenuate myocardial cell apoptosis in vitro, the effects of CSWT in vivo require future studies. Second, the best strategy of SW delivery remains to be elucidated. Our strategy was to shoot 500 shots/spot for ischemia and hypoxia in myocardial cells, whereas Aicher et al. [43] shot 500-2,000 shocks in one session. Further studies are required to determine the best treatment strategy.

In conclusion, we show here that CSWT exerts a protective effect against I/H-induced cell death and demonstrate that this may occur by preventing the activation of components of the mitochondrial-dependent intrinsic apoptotic pathway. We also demonstrate that the PI3K-Akt pathway may be involved in the effects of CSWT on apoptosis. Together with further work on this topic, our study demonstrates that CSWT is a prospective intervention for ischemic heart disease.

\section{Acknowledgments}

We would like to thank the Beijing Hospital Ministry of Health Institute of Geriatric Medicine Biochemical Laboratory for providing us with excellent facilities for our experimental studies. This work was supported by grants from projects supported by the Capital Health Project (Z131100004013032).

\section{References}

1 Jessup M, Brozena S: Heart failure. N Engl J Med 2003;348:2007-2018.

2 Morrison D, Sacks J: Balancing benefit against risk in the choice of therapy for coronary artery disease: lesson from prospective, randomized, clinical trials of percutaneous coronary intervention and coronary artery bypass graft surgery. Minerva Cardioangiol 2003;51:585-597.

3 Angina R: The problem of chronic refractory angina. Eur Heart J 2002;23:355-370. 


\section{Cellular Physiology and Biochemistry}

Cell Physiol Biochem 2014;33:1293-1303

\begin{tabular}{l|l}
\hline DOI: $10.1159 / 000358697$ & (C) 2014 S. Karger AG, Basel
\end{tabular}

Yu et al.: CSWT Attenuates Cell Apoptosis

- 4 Nishida T, Shimokawa H, Oi K, Tatewaki H, Uwatoku T, Abe K, Matsumoto Y, Kajihara N, Eto M, Matsuda T: Extracorporeal cardiac shock wave therapy markedly ameliorates ischemia-induced myocardial dysfunction in pigs in vivo. Circulation 2004;110:3055-3061.

5 Ito K, Fukumoto Y, Shimokawa H: Extracorporeal shock wave therapy as a new and non-invasive angiogenic strategy. Tohoku J Exp Med 2009;219:1-9.

-6 Fukumoto Y, Ito A, Uwatoku T, Matoba T, Kishi T, Tanaka H, Takeshita A, Sunagawa K, Shimokawa H: Extracorporeal cardiac shock wave therapy ameliorates myocardial ischemia in patients with severe coronary artery disease. Coron Artery Dis 2006;17:63-70.

7 Olivetti G, Quaini F, Sala R, Lagrasta C, Corradi D, Bonacina E, Gambert S, Cigola E, Anversa P: Acute myocardial infarction in humans is associated with activation of programmed myocyte cell death in the surviving portion of the heart. J Mol Cell Cardiol 1996;28:2005-2016.

-8 Saraste A, Pulkki K, Kallajoki M, Henriksen K, Parvinen M, Voipio-Pulkki L-M: Apoptosis in human acute myocardial infarction. Circulation 1997;95:320-323.

\9 Narula J, Haider N, Virmani R, DiSalvo TG, Kolodgie FD, Hajjar RJ, Schmidt U, Semigran MJ, Dec GW, Khaw BA: Apoptosis in myocytes in end-stage heart failure. N Engl J Med 1996;335:1182-1189.

10 Guerra S, Leri A, Wang X, Finato N, Di Loreto C, Beltrami CA, Kajstura J, Anversa P: Myocyte death in the failing human heart is gender dependent. Circ Res 1999;85:856-866.

11 Yaoita H, Ogawa K, Maehara K, Maruyama Y: Attenuation of ischemia /reperfusion injury in rats by a caspase inhibitor. Circulation 1998;97:276-281.

$\rightarrow 12$ Holly TA, Drincic A, Byun Y, Nakamura S, Harris K: Caspase inhibition reduces myocyte cell death induced by myocardial ischemia and reperfusion in vivo. J Mol Cell Cardiol 1999;31:1709-1715.

-13 Huang JQ, Radinovic S, Rezaiefar P, Black SC: In vivo myocardial infarct size reduction by a caspase inhibitor administered after the onset of ischemia. Eur J Pharmacol 2000;402:139-142.

14 Wencker D, Chandra M, Nguyen K: A mechanistic role for cardiac myocyte apoptosis in heart failure. J Clin Invest 2003;111:1497-1504.

$>15$ Tao Shen, Yuping Zhu, Jigar Patel, Yang Ruan, Beidong Chen, Gexin Zhao, Yuan Cao, Jing Pang, Hangbang Guo, Hongxia Li, Yong Man, Shu Wang, Jian Li: T-Box20 Suppresses Oxidized Low-Density Lipoproteininduced Human Vascular Endothelial Cell Injury by Upregulation of PPAR- $\gamma$. Cell Physiol Biochem 2013;32:1137-1150.

16 Hescheler J, Meyer R, Plant S, Krautwurst D, Rosenthal W, Schultz G. Morphological, biochemical, and electrophysiological characterization of a clonal cell (H9c2) line from rat heart. Circ Res 1991;69:14761486.

17 Liu X-h, Chen P-f, Pan L-l, De Silva R, Zhu Y-z. 4-Guanidino-n-butyl syringate (Leonurine, SCM 198) protects H9c2 rat ventricular cells from hypoxia-induced apoptosis. J Cardiovasc Pharmacol 2009;54:437-444.

18 Bonavita F, Stefanelli C, Giordano E, Columbaro M, Facchini A, Bonafè F, et al. H9c2 cardiac myoblasts undergo apoptosis in a model of ischemia consisting of serum deprivation and hypoxia: inhibition by PMA. FEBS Lett 2003;536:85-91.

19 Ekhterae D, Lin Z, Lundberg MS, Crow MT, Brosius FC, Núñez G. ARC inhibits cytochrome c release from mitochondria and protects against hypoxia-induced apoptosis in heart-derived H9c2 cells. Circ Res 1999;85:e70-e7.

-20 Vasyuk YA, Hadzegova AB, Shkolnik EL, Kopeleva MV, Krikunova OV, Iouchtchouk EN, Aronova EM, Ivanova SV: Initial clinical experience with extracorporeal shock wave therapy in treatment of ischemic heart failure. Congest Heart Fail 2010;16:226-230.

-21 Schmid JP, Capoferri M, Wahl A, Eshtehardi P, Hess OM: Cardiac Shock Wave Therapy for Chronic Refractory Angina Pectoris. A Prospective Placebo-Controlled Randomized Trial. Cardiovasc Ther 2013;31:e1-e6.

-22 Kazmi WH, Rasheed SZ, Ahmed S, Saadat M, Altaf S, Samad A: Noninvasive therapy for the management of patients with advanced coronary artery disease. Coron Artery Dis 2012;23:549-554.

-23 Sobczak M, Kasprzak JD: Cardiac shock wave therapy--a new method for treatment of advanced coronary disease and refractory angina. Kardiol Pol 2010;68:1391.

24 Gutersohn A, Caspari G, Erbel R: Short and long term clinical improvement in patients with refractory angina using cardiac shock wave therapy (CSWT). Circ J 2005;69:S378.

-25 Tanaka M, Ito H, Adachi S, Akimoto H, Nishikawa T, Kasajima T, Marumo F, Hiroe M: Hypoxia induces apoptosis with enhanced expression of Fas antigen messenger RNA in cultured neonatal rat cardiomyocytes. Circ Res 1994;75:426-433. 


\section{Cellular Physiology and Biochemistry}

Cell Physiol Biochem 2014;33:1293-1303

Yu et al.: CSWT Attenuates Cell Apoptosis

-26 Kajstura J, Cheng W, Reiss K, Clark WA, Sonnenblick EH, Krajewski S, Reed JC, Olivetti G, Anversa P: Apoptotic and necrotic myocyte cell deaths are independent contributing variables of infarct size in rats. Lab Invest 1996;74:86-107.

-27 Leri A, Claudio PP, Li Q, Wang X, Reiss K, Wang S, Malhotra A, Kajstura J, Anversa P: Stretch-mediated release of angiotensin II induces myocyte apoptosis by activating p53 that enhances the local reninangiotensin system and decreases the Bcl-2-to-Bax protein ratio in the cell. J Clin Invest 1998;101:1326.

-28 Scorrano L, Ashiya M, Buttle K, Weiler S, Oakes SA, Mannella CA, Korsmeyer SJ: A Distinct Pathway Remodels Mitochondrial Cristae and Mobilizes Cytochrome c during Apoptosis. Dev Cell 2002;2:55-67.

-29 Tatsumi T, Shiraishi J, Keira N, Akashi K, Mano A, Yamanaka S, Matoba S, Fushiki S, Fliss H, Nakagawa $\mathrm{M}$ : Intracellular ATP is required for mitochondrial apoptotic pathways in isolated hypoxic rat cardiac myocytes. Cardiovasc Res 2003;59:428-440.

-30 Kluck RM, Bossy-Wetzel E, Green DR, Newmeyer DD: The release of cytochrome c from mitochondria: a primary site for Bcl-2 regulation of apoptosis. Science 1997;275:1132-1136.

-31 Yang J, Liu X, Bhalla K, Kim CN, Ibrado AM, Cai J, Peng TI, Jones DP, Wang X: Prevention of apoptosis by Bcl2: release of cytochrome c from mitochondria blocked. Science 1997;275:1129-1132.

-32 Misao J, Hayakawa Y, Ohno M, Kato S, Fujiwara T, Fujiwara H: Expression of bcl-2 protein, an inhibitor of apoptosis, and Bax, an accelerator of apoptosis, in ventricular myocytes of human hearts with myocardial infarction. Circulation 1996;94:1506-1512.

-33 Nishikawa S, Tatsumi T, Shiraishi J, Matsunaga S, Takeda M, Mano A, Kobara M, Keira N, Okigaki M, Takahashi T: Nicorandil regulates Bcl-2 family proteins and protects cardiac myocytes against hypoxiainduced apoptosis. J Mol Cell Cardiol 2006;40:510-519.

-34 Uwatoku T, Ito K, Abe K, Oi K, Hizume T, Sunagawa K, Shimokawa H: Extracorporeal cardiac shock wave therapy improves left ventricular remodeling after acute myocardial infarction in pigs. Coron Artery Dis 2007;18:397-404.

-35 Yao R, Cooper GM: Requirement for phosphatidylinositol-3 kinase in the prevention of apoptosis by nerve growth factor. Science 1995;267:2003-2006.

-36 Gajewski TF, Thompson CB: Apoptosis meets signal transduction: elimination of a BAD influence. Cell 1996;87:589-592.

-37 del Peso L, González-Garcıa M, Page C, Herrera R, Nuñez G: Interleukin-3-induced phosphorylation of BAD through the protein kinase Akt. Science 1997;278:687-689.

-38 Datta SR, Dudek H, Tao X, Masters S, Fu H, Gotoh Y, Greenberg ME: Akt phosphorylation of BAD couples survival signals to the cell-intrinsic death machinery. Cell 1997;91:231-241.

-39 Jargin SV: Shock wave therapy of ischemic heart disease in the light of general pathology. Int J Cardiol 2010;144:116-117.

40 Jargin SV: Shock wave therapy of ischemic heart disease: some aspects of publication and advertizing in Russia. Int J Cardiol 2010;145:241-242.

-41 Di Meglio F, Nurzynska D, Castaldo C, Miraglia R, Romano V, De Angelis A, Piegari E, Russo S, Montagnani S: Cardiac shock wave therapy: assessment of safety and new insights into mechanisms of tissue regeneration. J Cell Mol Med 2012;16:936-942.

-42 Fu M, Sun C-K, Lin Y-C, Wang C-J, Wu C-J, Ko S-F, Chua S, Sheu J-J, Chiang C-H, Shao P-L, Leu S, Yip H-K: Extracorporeal shock wave therapy reverses ischemia-related left ventricular dysfunction and remodeling: molecular-cellular and functional assessment. PLoS One 2011;6:e24342.

43 Aicher A, Heeschen C, Sasaki K-i, Urbich C, Zeiher AM, Dimmeler S: Low-Energy Shock Wave for Enhancing Recruitment of Endothelial Progenitor Cells A New Modality to Increase Efficacy of Cell Therapy in Chronic Hind Limb Ischemia. Circulation 2006;114:2823-2830. 